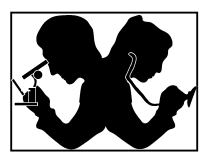

\title{
The enigma of sepsis
}

\author{
Niels C. Riedemann, Ren-Feng Guo, and Peter A. Ward \\ Department of Pathology, University of Michigan Medical School, Ann Arbor, Michigan, USA
}

Sepsis remains a serious cause of morbidity and mortality, and the pathophysiology of the disease is not clear. The definition of the clinical manifestations of sepsis is ever evolving. This review discusses the search for effective therapeutic interventions, hurdles in translational sepsis research, and new therapies in development in current clinical trials.

J. Clin. Invest. 112:460-467 (2003). doi:10.1172/JCI200319523.

\section{Historical perspective and definition}

Sepsis affects approximately 700,000 people annually and accounts for about 210,000 deaths per year in the US. According to recent reports, the incidence is rising at rates between $1.5 \%$ and $8 \%$ per year $(1,2)$, despite technical developments in intensive care units (ICUs) and advanced supportive treatment. Septic patients are generally hospitalized for extended periods, rarely leaving the ICU before 2-3 weeks. Accordingly, sepsis represents a major burden to the US health care system, with costs estimated to be approximately $\$ 16.7$ billion per year (1). The question of why the incidence is rising has been extensively discussed, but a final answer has not yet been found. Interestingly, the spectrum of responsible microorganisms appears to have shifted from predominantly Gram-negative bacteria in the late 1970 s and 1980 s to predominantly Gram-positive bacteria at present (2). In addition, the rate of fungal infections is reported to have increased more than $200 \%$ during the same period (2). As difficult as the treatment of septic patients and the improvement of their survival rates have been, equally difficult has been

The Science in Medicine series is supported in part by a generous grant from the Doris Duke Charitable Foundation.

Address correspondence to: Peter A. Ward, Department of Pathology, University of Michigan Medical School,

1301 Catherine Road, Ann Arbor, Michigan 48109-0602, USA.

Phone: (734) 763-6384; Fax: (734) 763-4782;

E-mail: pward@umich.edu.

Conflict of interest: The authors have declared that no conflict of interest exists.

Nonstandard abbreviations used: intensive care unit (ICU); systemic inflammatory response syndrome (SIRS); predisposition, insult, response, organ dysfunction (PIRO); cecal ligation and puncture (CLP); activated protein C (APC); plasminogen activator inhibitor-1 (PAI-1); monocyte chemoattractant protein-1 (MCP-1); high-mobility group B-1 protein (HMGB1); macrophage migration inhibitory factor (MIF); C5a receptor $(\mathrm{C} 5 \mathrm{aR})$; tissue factor plasminogen inhibitor (TFPI). the development of a clear clinical definition of sepsis. The lack of consensus regarding a definition has resulted in great difficulties in making meaningful comparisons of study results. Often, the lack of a precise definition of sepsis has also compromised the reproducibility of results of phase I clinical trials since the patient populations being studied were nonhomogeneous. An analysis of studies in recent years has demonstrated that the risk of death (and therefore the severity of disease) significantly correlates with the effectiveness of anti-inflammatory treatment (3). This finding implies a need for a better clinical definition of the disease in order for patients to be enrolled in treatment groups with well-defined entry criteria. In other words, the exact clinical status of each patient needs to be established.

For nearly a century, sepsis has been defined as the systemic host response to an infection, and even though many subclassifications have been made over the years, there has been little modification of this definition. Originally, sepsis was believed to be associated with the presence of bacteria in the blood (bacteremia), and the terms "sepsis" and "septicemia" were frequently interchanged in the clinical setting. In 1989, Bone et al. established a simple definition for sepsis syndrome, which was based on specific clinical symptoms and included a known source of infection (4). The clinical signs of sepsis, however, were frequently presented by patients not characterized by measurable levels of bacteria in the blood, or by those with acute pancreatitis (5) or trauma (6). This discrepancy was first taken into account at a Consensus Conference held by the Society of Critical Care Medicine and the American College of Chest Physicians in 1992, when the term "systemic inflammatory response syndrome" (SIRS) was established (Table 1), for which no definable presence of bacterial infection was required $(7,8)$. In addition, the terms "severe sepsis" and "septic shock" were introduced to differentiate 
between different stages of disease. The criteria for the various clinical definitions shown in Table 1 have been well established in clinical use.

However, discussion at the most recent consensus conference led to the addition of several new criteria for the diagnosis of SIRS and sepsis (Table 2) (9). This was due in part to the documentation of additional clinical symptoms and laboratory findings that are frequently present in patients with acute systemic response to infection or other insults. At this same consensus conference, the definitions of SIRS, sepsis, severe sepsis, and septic shock, including multiple organ dysfunction syndrome established in 1992 were endorsed. It can be argued that the earlier definitions did not facilitate the diagnosis of precise stages of disease or allow for accurate prognosis of the host response to infection. Therefore, a new staging system has been developed, similar to that used to stage tumor progression. The PIRO staging system facilitates a more accurate characterization of the stage of sepsis disease and the associated risks and prognosis. We endorse the introduction of the PIRO system for diagnosing and tracking sepsis progression, which characterizes the disease based on predisposition (especially to genetic factors), the insult infection (especially the type of infection, source, etc.), the response of the host system (SIRS, septic shock, etc.; specific markers like IL-6, protein C, TNF, etc.), and organ dysfunction (9). This classification would take into account the clinical status of the patient in addition to biochemical analyses. This should ultimately permit more precise classification of sepsis-related disorders and might be particularly helpful in more closely defining entry criteria for clinical trials of sepsis therapies.

\section{Early experimental basis for clinical anti-inflammatory therapeutic interventions}

The idea that sepsis was caused by an overwhelming reaction of the patient to invading microorganisms was probably at least partially based on the observation that, on many occasions, no clinical evidence for infection (e.g., positive bacterial blood cultures) was found in patients with septic symptoms. In 1972, Lewis Thomas noted in The New England Journal of Medicine that "it is our response that makes the disease" and that the patient was, therefore, more endangered by this response than by the invading microorganisms (10). According to this view, interventions designed to attenuate immune and inflammatory responses might be clinically useful. In the 1960s, the first clinical trials featuring suppression of the immune and inflammatory responses were conducted, in which septic patients were treated with supraphysiological doses of glucocorticoids (11) (Table 3). However, these studies were unsuccessful, despite the fact that more recent studies have suggested benefits from low-dose glucocorticoid treatment (see "Failure of clinical trials in sepsis").

As mentioned above, the predominant source of infection in septic patients before the late 1980s was Gram-negative bacteria. LPS, the main component of the Gram-negative bacterial cell wall, was known to stimulate release of inflammatory mediators from various cell types and induce acute infectious symptoms when injected into animals. In 1969, Davis and colleagues found that infusion of IgGs improved survival in an experimental setting after endotoxin infusion (12). Based on these and other findings, LPS blockade became a target for clinical intervention (13).

Given the frequency of Gram-negative infections in septic patients, it was assumed that large amounts of circulating LPS must be present. Based on this assumption, animal models of sepsis were established mainly in rodents, in which large doses of LPS had been administered. In contrast to the responses observed following bacterial infection (e.g., bacteria delivered by intraperitoneal or i.v. injection, or released into the peritoneal cavity in the cecal ligation and puncture [CLP] model), LPS infusion models often did not mimic the changes observed during sepsis (Figure 1). This fact became apparent in the case of TNF- $\alpha$, a potent proinflammatory mediator. In addition, infusion of TNF- $\alpha$ into animals induced the symptoms

Table 1

Clinical definition of sepsis

$\begin{array}{ll}\text { SIRS } & \text { Temperature }>38.3^{\circ} \mathrm{C} \text { or }<36^{\circ} \mathrm{C} \\ & \text { Heart rate }>90 \text { beats } / \mathrm{min} \\ & \text { Respiratory rate }>20 \text { breaths } / \mathrm{min} \text { or } \mathrm{PaCO}_{2}<32 \mathrm{mmHg} \\ & \text { White blood cell count }>12 \times 10^{9} / \mathrm{l} \text { or }<4 \times 10^{9} / \mathrm{l}, \text { or }>10 \% \text { immature band forms } \\ \text { Sepsis } & \text { Systemic response to infection, manifested by two or more of the conditions mentioned under SIRS } \\ \text { Severe sepsis } & \text { SIRS + evidence of infection) } \\ \text { Septic shock } & \begin{array}{l}\text { Sepsis associated with organ dysfunction, hypoperfusion, or hypotension including lactic acidosis, } \\ \text { oliguria, or acute alteration in mental state }\end{array} \\ & \begin{array}{l}\text { Sepsis-induced hypotension (e.g., systolic blood pressure }<90 \mathrm{mmHg} \text { or a reduction of }>40 \mathrm{mmHg} \text { from base line) } \\ \text { despite adequate fluid resuscitation, along with the presence of perfusion abnormalities that may include lactic acidosis, } \\ \text { oliguria, or an acute alteration in mental state. Vasopressor- or inotropic-treated patients may not be hypotensive } \\ \text { at the time of measurement }\end{array} \\ \text { MODS } & \text { The presence of altered organ function in an acutely ill patient such that homeostasis cannot be maintained } \\ & \text { without intervention }\end{array}$

$\mathrm{PaCO}_{2}$, arterial partial pressure of carbon dioxide; MODS, multiple organ dysfunction syndrome. 
characteristic of sepsis (14), while passive immunization with anti-TNF- $\alpha$ was protective $(15,16)$. High levels of TNF- $\alpha$ have been found in the serum of humans following i.v. injection of LPS (15). In 1985, Beutler and colleagues found that passive immunization against TNF- $\alpha$ protected mice from lethal endotoxic shock (16). These results were confirmed when Tracey et al. found that TNF- $\alpha$ blockade was beneficial in animal models of shock following infusion of endotoxin or Escherichia coli $(17,18)$. But subsequent clinical trials failed to demonstrate the utility of this therapy in septic humans (19) and in CLP mice (20). Why?

One possible explanation is that the results obtained from studies performed in LPS infusion animal models did not accurately reflect clinical developments in human sepsis. Serum TNF- $\alpha$ levels after infusion of LPS into mice were later described to be more than 200-fold higher than in CLP animals (20). In a similar study, CLP mice treated with antiTNF- $\alpha$ antibodies showed not improved survival but, rather, a tendency toward worsened outcomes (21). Interestingly, the circulating LPS levels in the CLP sepsis model (which more accurately reflects the dynamics of sepsis occurring in humans) were found to be very low, and extreme elevations of TNF- $\alpha$ levels were not observed in rodent LPS infusion models (21). As indicated above, TNF- $\alpha$ levels observed in CLP models are generally very low and not comparable to TNF- $\alpha$ levels found after LPS infusion. In addition, LPS levels in septic patients are also reported to be low, and while in some cases of sepsis in humans (e.g., meningococcal sepsis in infants) elevated serum levels of TNF- $\alpha$ have been found in up to $90 \%$ of patients (22), several other clinical studies in septic patients reported only minimally elevated or undetectable levels of TNF- $\alpha$ (23). The failure of antiTNF- $\alpha$ and anti-LPS interventions in septic patients can be seen as an example of how conclusions based on animal models may not hold true in humans, or may not be applicable to human sepsis because of incorrect assumptions underlying the animal models (e.g., that LPS is a major initiator of sepsis and is present in the serum at high levels during sepsis) (Figure 1). Currently, there is general agreement among researchers in the field that LPS injection may serve as a model for endotoxic shock but not for sepsis.

\section{Failure of clinical trials in sepsis}

The nearly 40-year history of clinical trials of antiinflammatory strategies for the treatment of sepsis might be referred to as a "graveyard" for pharmaceutical companies, since almost none of these strategies has resulted in significantly improved survival of patients. In Table 3 the anti-inflammatory strategies used in clinical trials are summarized. The various strategies are discussed in detail elsewhere $(23,24)$. Often, promising initial results from small uncontrolled phase I or II clinical trials subsequently could not be confirmed in larger randomized clinical trials. The possible reasons are numerous. Some of these failures resulted from the use

\section{Table 2}

Extended criteria for the diagnosis of sepsis

General variables

Inflammatory variables

Hemodynamic variables

Organ dysfunction

Tissue perfusion

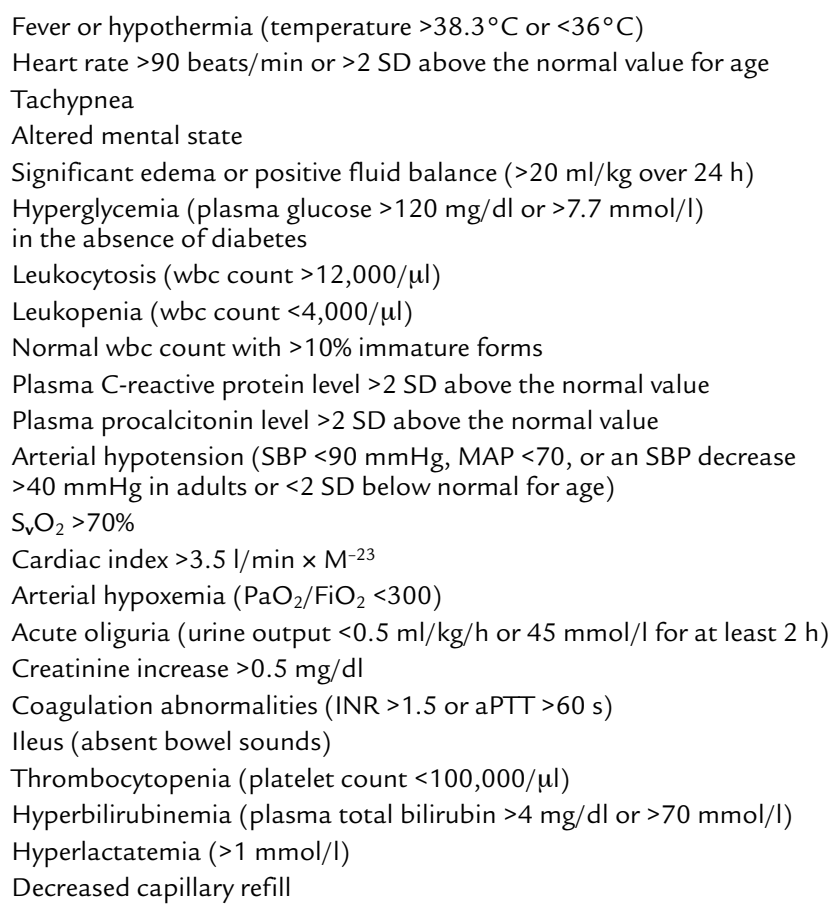

Fever or hypothermia (temperature $>38.3^{\circ} \mathrm{C}$ or $<36^{\circ} \mathrm{C}$ ) Tachypnea

Altered mental state

Hyperglycemia (plasma glucose $>120 \mathrm{mg} / \mathrm{dl}$ or $>7.7 \mathrm{mmol} / \mathrm{l}$ )

in the absence of diabetes

Leukocytosis (wbc count $>12,000 / \mu$ )

Leukopenia ( $w b c$ count $<4,000 / \mu l$ )

Normal wbc count with $>10 \%$ immature forms

Plasma C-reactive protein level $>2$ SD above the normal value

Plasma procalcitonin level $>2$ SD above the normal value

$>40 \mathrm{mmHg}$ in adults or $<2 \mathrm{SD}$ below normal for age

$\mathrm{S}_{\mathrm{v}} \mathrm{O}_{2}>70 \%$

Cardiac index $>3.5 \mathrm{I} / \mathrm{min} \times \mathrm{M}^{-23}$

Arterial hypoxemia $\left(\mathrm{PaO}_{2} / \mathrm{FiO}_{2}<300\right)$

Acute oliguria (urine output $<0.5 \mathrm{ml} / \mathrm{kg} / \mathrm{h}$ or $45 \mathrm{mmol} / \mathrm{l}$ for at least $2 \mathrm{~h}$ )

Creatinine increase $>0.5 \mathrm{mg} / \mathrm{dl}$

Coagulation abnormalities (INR $>1.5$ or aPTT $>60 \mathrm{~s}$ )

Ileus (absent bowel sounds)

Thrombocytopenia (platelet count $<100,000 / \mu$ )

Hyperlactatemia (>1 mmol/l)

Decreased capillary refil

wbc, white blood cell; SBP, systolic blood pressure; MAP, mean arterial pressure; $\mathrm{S}_{\mathrm{v}} \mathrm{O}_{2}$, mixed venous oxygen saturation; PaO $\mathrm{O}_{2}$, arterial partial pressure of oxygen; $\mathrm{FiO}_{2}$, fraction of inspired oxygen; INR, international normalized ratio; aPTT, activated partial thromboplastin time. 
of unsuitable animal models (LPS infusion) and wrong assumptions, as discussed previously. In the case of glucocorticoids, follow-up studies in the 1990s suggested that lower doses of glucocorticoids might be beneficial in septic patients. In 2001, a large multicenter phase III clinical trial was completed, which suggested that 7-day treatment with low doses of hydrocortisone and fludrocortisone significantly reduced the risk of death in patients with septic shock who also demonstrated relative adrenal insufficiency (25). Such benefits, however, were not reported in patients who lacked evidence of adrenal insufficiency. Thus, in this case, the dose of the therapeutic intervention as well as the patient group appeared to determine failure or success.

Retrospectively, a crucial problem in most of the clinical trials investigating anti-inflammatory agents appears to be the nonhomogeneity of the patient population enrolled, which partially stems from an inability to more effectively classify the immune status of the septic patient. The recent finding that the success of anti-inflammatory treatments in animals and humans with sepsis closely correlates with the severity of disease (3) may explain why some trials report benefits (especially those with patients in severe sepsis or septic shock) while others do not.

The immune system in a septic individual undergoes substantial modifications during sepsis. Experimental data support the theory that an early intense proinflammatory response of the immune system after infection or trauma can cause harm or set the stage for subsequent organ damage, but it is also well documented that, during sepsis, the innate immune system frequently loses the ability to effectively kill invading microorganisms (26). Depending on the ability of the immune system to respond to infection, an anti-inflammatory strategy may not be helpful and could even be harmful, as in the clinical trial in which a TNF- $\alpha$ antagonist was reported to increase mortality (27).

Table 3

Targets in clinical trials for the treatment of sepsis

Immune modulation

Endotoxin (LPS)

TNF- $\alpha$

IL-1

PAF

Bradykinin

Arachidonic acid metabolites

Reactive oxygen species

NO

Phosphodiesterase Neutrophil activity

Complement system Coagulation

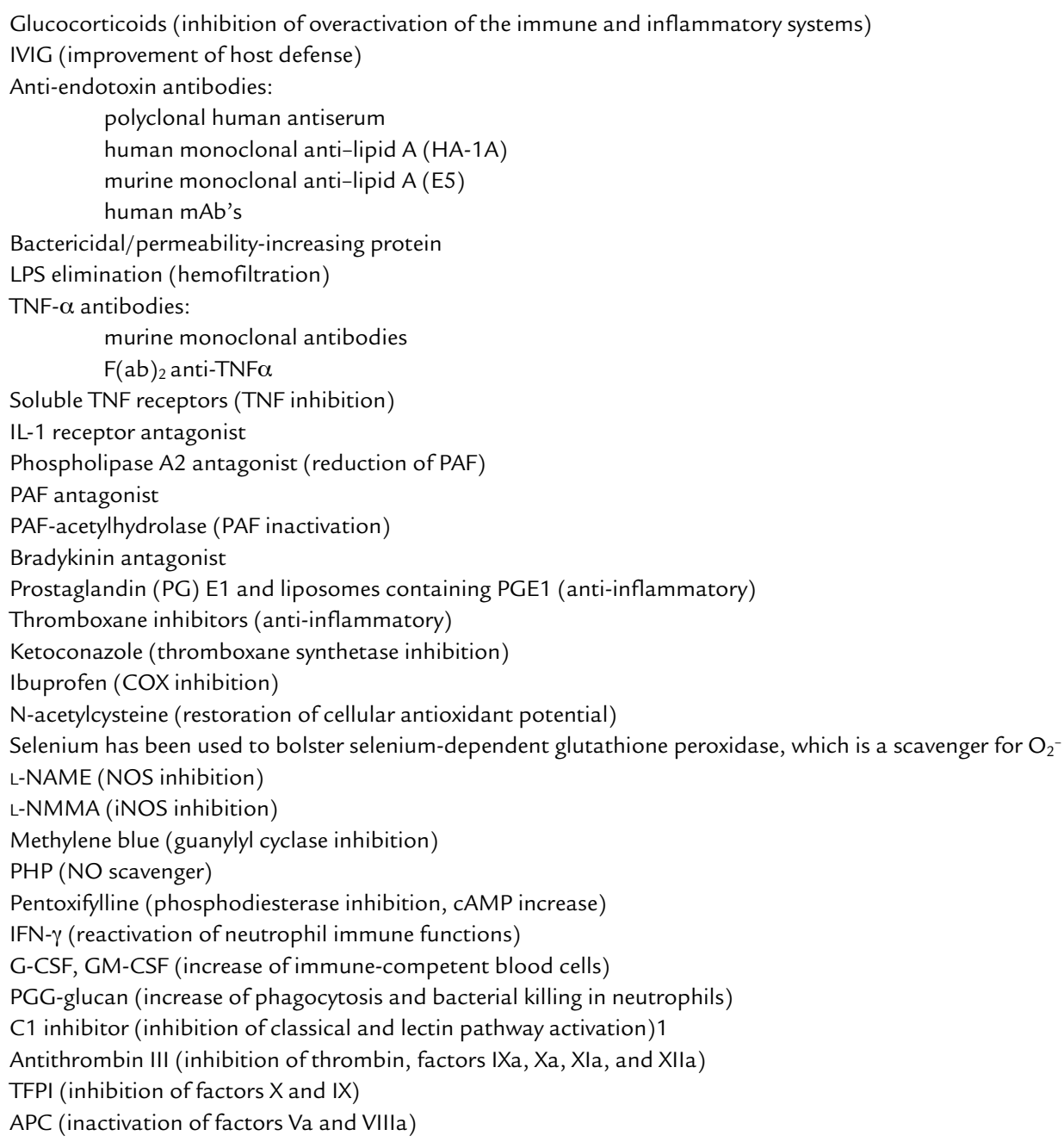

IVIG, intravenous IgG; PAF, platelet-activating factor; PGE1, prostaglandin E1; L-NAME, $N$-nitro-L-arginine methyl ester; L-NMMA, $N(G)$-monomethylL-arginine; PHP, pyridoxylated hemoglobin polyoxyethylene conjugate; PGG, poly-(1-6)- $\beta$-glucotriosyl-(1-3)- $\beta$-glucopyranose; APC, activated protein C. 
The new PIRO scoring system can be seen as an attempt to stage a septic patient, with the ultimate goal of treating sepsis according to the patient's immunological status. A substantial hurdle will be development of diagnostic tools that facilitate an efficient and accurate determination of this status.

\section{The mysterious success of activated protein C}

In November 2001, drotrecogin alfa (Xigris), a recombinant form of activated protein C (APC), was approved by the US Food and Drug Administration for the treatment of patients with severe sepsis. The original large multicenter randomized trial, known as Protein C World Wide Evaluation in $\underline{\text { Severe }}$ Sepsis (PROWESS), that evaluated the utility of this drug against sepsis

\section{Assumptions}

1. Gram-negative bacteria are cause of sepsis infection

2. Bacteria causing disease shed LPS

3. High levels of serum LPS achieved in septic patients

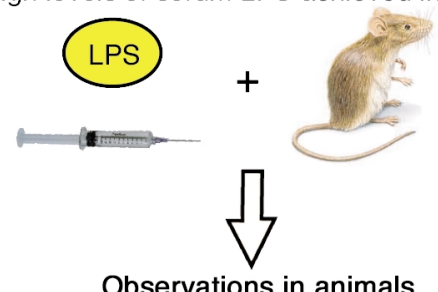

1. High serum levels of TNF- $\alpha$ achieved following LPS infusion

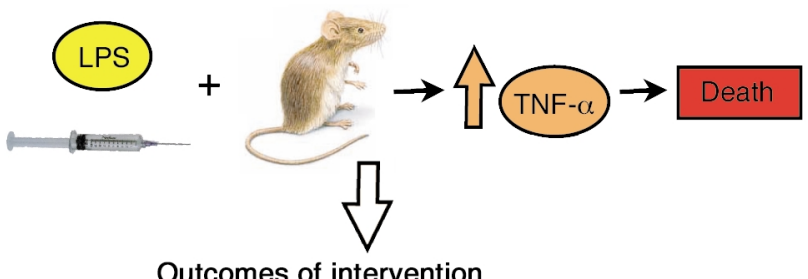

1. Treatment with anti-TNF- $\alpha$ antibodies increases survival

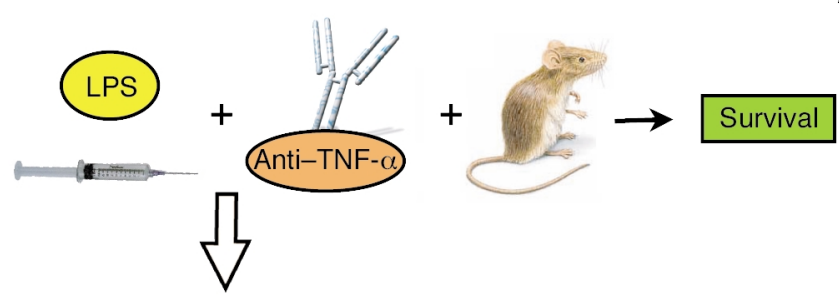

Clinical trials in humans with sepsis

1. Anti-TNF- $\alpha$ antibodies not protective
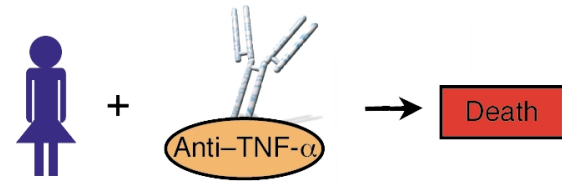

(27-29) revealed an overall reduction of $19.4 \%$ in the relative risk of death and a reduction of $6.1 \%$ in the absolute risk of death $(30.8 \%$ mortality at 28 days in the placebo group vs. $24.7 \%$ with drotrecogin alfa). A detailed analysis revealed that only patients with a high risk of death (APACHE II scores $\geq 25$ ) showed significantly reduced mortality, by $13 \%$ (44\% mortality with placebo vs. $31 \%$ with drotrecogin alfa). Concerns emerged regarding infrequent bleeding complications (intracerebral hemorrhage) that occurred when the recommended doses of APC were used. Warnings were added to the labels for drotrecogin alfa, stating that its efficacy in septic infants, and its safety for severely septic patients receiving concomitant heparin, were unknown. The recently started $\underline{\text { Administration of Drotre- }}$

\section{Possible reasons for failure}

1. Incorrect assumptions based on initiating factors of disease 2. Incomplete clinical observations

1. Unsuitable animal model, not translatable to humans

2. High serum levels of TNF- $\alpha$ not achieved in humans during sepsis
1. Unable to block all TNF- $\alpha$
2. Results incorrect

\section{Figure 1}

Possible reasons for failure in sepsis trials. The flow diagram reflects various stages in the development of sepsis therapies that precede clinical trials in sepsis patients. At each stage, possible reasons for failure of the strategy are listed. The murine LPS infusion model illustrates that anti-TNF- $\alpha$ antibody treatment can successfully increase survival rates of septic animals; however, this same therapy proved unsuccessful in clinical trials in humans with sepsis. 
cogin Alfa in Early Severe Sepsis trial (ADDRESS) will be the largest clinical sepsis trial in history, aiming to enroll 11,000 patients to determine the potential benefits of this drug in septic patients with a lower risk of death and with dysfunction involving only one major organ (lungs, liver, or kidneys).

Thrombin, after binding to thrombomodulin on the cell surface of endothelial cells, can activate plasma protein $\mathrm{C}$, which, together with its cofactor protein $\mathrm{S}$, then functions as a proteolytic inhibitor of the clotting factors Va and VIIIa, thereby acting as an anticoagulant. In addition, APC is a powerful anti-inflammatory molecule capable of inhibiting cytokine production (TNF- $\alpha$, IL-1, and IL-6) in monocytes and reducing adhesive interactions between neutrophils and endothelial cells (30). APC also indirectly increases the fibrinolytic response by inhibiting plasminogen activator inhibitor-1 (PAI-1). In humans with sepsis, plasma levels of proteins $\mathrm{C}$ and $\mathrm{S}$ fall significantly, and thrombomodulin present on endothelial cells is downregulated, leading to reduced APC generation. A recent study demonstrated that APC employs the endothelial cell protein $\mathrm{C}$ receptor as a coreceptor for cleavage of protease-activated receptor-1 (PAR-1) on endothelial cells (30). The study suggests that APC may play a role in cell signaling and gene transcription of protective genes through selective PAR-1 activation on endothelial cells and related induction of monocyte chemoattractant protein-1 (MCP-1), which protects cells. Treatment of sepsis with APC is associated with a risk of significant complications (e.g., intracerebral bleeding) and is therefore the subject of intensive debate (30-32).

The mechanisms by which APC treatment improves survival in humans cannot be explained at this time. So far, significant reductions in mortality have been observed only in patients with severe sepsis, who seem to be more likely to benefit from anti-inflammatory strategies. Given this fact, one might speculate that the anti-inflammatory potential of APC provides protection in severely septic patients, especially since other anticoagulant strategies, such as antithrombin III and tissue factor plasminogen inhibitor (TFPI), have not resulted in significant benefits (ref. 33 and Table 3 ).

\section{New strategies raise new hope}

The success of APC provides new hope that other new therapeutic strategies for the treatment of sepsis may be introduced into the clinic in the near future. The main target groups for anti-inflammatory treatment, according to the lessons learned, will likely be patients with severe sepsis or septic shock. Some new developments in the area of sepsis research appear to be specifically promising.

\section{Apoptosis inhibition}

Programmed cell death (apoptosis) is differentiated from cell necrosis by typical features, such as DNA fragmentation, condensation of chromatin, membrane blebbing, and cell shrinkage. Several proin- flammatory mediators (such as TNF- $\alpha$ ) produced during experimental sepsis are known inducers of apoptosis involving various cell types. During sepsis, lymphocytes have been shown to undergo rapid apoptosis, whereas other cells, like neutrophils, demonstrate delayed apoptosis $(34,35)$. Hotchkiss and colleagues recently demonstrated that the prevention of lymphocyte cell death during sepsis could improve outcome (35-37). Caspase inhibitors were found to be an effective tool to protect animals from death during pneumonia-induced sepsis (38). These findings led to the hypothesis that immunodepression resulting from the loss of lymphocytes could represent a central pathogenic event in sepsis. Further studies have suggested that inhibition of intestinal epithelial apoptosis (by selective $\mathrm{Bcl}-2$ overexpression) significantly improved outcomes in two different models of sepsis in mice $(38,39)$. Recently it was demonstrated that adoptive transfer of apoptotic splenocytes in septic mice worsened the outcome, while transfer of necrotic splenocytes had protective effects (40). The underlying mechanisms of these studies are not yet understood. Treatment of septic patients with apoptosis inhibitors has to overcome several problems, including the selectivity of such inhibitors and potential uncontrolled cell growth. However, the concept of regulated apoptosis warrants further investigation.

\section{High-mobility group B-1 protein}

Kevin Tracey and his group have recently demonstrated that high-mobility group B-1 protein (HMGB1) acts as a late mediator in LPS-induced endotoxicity $(41,42)$. HMGB1 was originally described as a nuclear binding protein, facilitating gene transcription by stabilizing nucleosome formation. HMGB1 can bind to the cellular receptor for advanced glycation end products (RAGE), facilitating activation of the transcription factor NF-кB and MAPK (43), and thereby inducing generation of proinflammatory mediators in monocytes (43). In endothelial cells, HMGB1 induces VCAM-1, ICAM-1, and RAGE expression, as well as secretion of TNF- $\alpha$, IL-8, MCP-1, PAI-1, and tissue plasminogen activator (44). A recent study found that HMGB1 increases the permeability in enterocytic monolayers and bacterial translocation to lymph nodes in mice in vivo (45). These findings demonstrate the proinflammatory potential of HMGB1 and its linkage to the coagulation system. Recently, ethyl pyruvate, which inhibits HMGB1 production in vivo, was found to improve survival in a sepsis model in mice when administered 24 hours after the onset of sepsis (46). This finding makes HMGB1 a potential therapeutic target for the treatment of sepsis.

\section{Macrophage migration inhibitory factor}

Blockade of macrophage migration inhibitory factor (MIF) or targeted disruption of the MIF gene significantly improved survival in a model of septic shock in mice $(47,48)$. Earlier studies found that administration 
of MIF induced greater lethality after LPS infusion (47, 48) and that MIF knockout mice demonstrated improved survival after endotoxin challenge and showed reduced levels of TNF- $\alpha$ (48).

MIF was originally described as a $\mathrm{T}$ cell cytokine and later found to be produced by other cells such as pituitary gland cells (49), eosinophils (50), tubular epithelial cells in kidney (51), epithelial cells in lung (52), and macrophages (53), in which glucocorticoids acted as strong inducers of MIF (54). MIF is capable of inducing production of various proinflammatory mediators in macrophages and other cells and thereby can override the glucocorticoid-induced inhibition of proinflammatory-cytokine production (54). Septic patients show elevated serum levels of $\operatorname{MIF}(55,56)$, as do patients with adult respiratory distress syndrome. In both cases, elevated levels of MIF are correlated with poor prognosis and death. Accordingly, MIF is an interesting target for therapeutic intervention in septic patients.

\section{$\mathrm{C5a}$ and $\mathrm{C5a}$ receptor}

The various complement pathways are activated on bacterial surfaces and by bacterial products such as LPS, by acute-phase proteins (e.g., C-reactive protein), by immune complexes, and by many other stimuli. Complement activation then results in assembly of the terminal membrane attack complex C5b-9, which forms pores in invading microorganisms and leads to their lysis. The anaphylatoxin C5a is cleaved from the complement protein $\mathrm{C} 5$ and exerts numerous proinflammatory effects, such as chemotactic responses of neutrophils (57), release of granular enzymes from phagocytic cells (58), neutrophil production of superoxide anion (59), vasodilatation, increased vascular permeability (60), and induction of thymocyte apoptosis during sepsis $(61,62)$.

Blockade of C5a generation with antibodies during the onset of sepsis in rodents has been shown to greatly improve survival (63). Similar findings were made when the $\mathrm{C} 5 \mathrm{a}$ receptor $(\mathrm{C} 5 \mathrm{aR})$ was blocked, either with antibodies or with a small molecular inhibitor $(64,65)$. Earlier experimental studies in monkeys have suggested that antibody blockade of C5a attenuated E. coliinduced septic shock and adult respiratory distress syndrome $(66,67)$. In humans with sepsis, C5a was elevated and associated with significantly reduced survival rates together with multiorgan failure, when compared with that in less severely septic patients and survivors (68-70). The mechanisms by which C5a exerts its harmful effects during sepsis are yet to be investigated in greater detail, but recent data suggest that generation of C5a during sepsis significantly compromises innate immune functions of blood neutrophils $(71,72)$, their ability to express a respiratory burst, and their ability to generate cytokines (73). In addition, C5a generation during sepsis appears to have procoagulant effects (74). The concept of blockade of $\mathrm{C} 5 \mathrm{a} / \mathrm{C} 5 \mathrm{aR}$ during sepsis therefore has therapeutic potential, especially in the context of prevention of development of sepsis.

\section{Conclusion}

The definition of sepsis appears to be very complicated because of the nonhomogenous nature of the patient populations studied and of the underlying conditions related to sepsis. The difficulties in precise clinical classification of septic patients could at least partially explain the failure of so many clinical trials that have used anti-inflammatory strategies. Therapeutic interventions are currently considered more likely to be successful in patients who exhibit severe sepsis or septic shock. Recent clinical studies suggested that early aggressive-volume resuscitation is beneficial in patients with severe sepsis or septic shock (75). Intensive insulin therapy for critically ill diabetic patients has reduced the frequency of occurrence of sepsis by $46 \%$ and lowered the mortality in patients with bacteremia (76). Significant improvements in supportive treatment in ICUs (e.g., more specific antibiotic treatment, improved mechanical ventilation, improved monitoring of circulation, etc.) are mainly responsible for improvements in survival statistics of septic patients. Still, the incidence of sepsis is rising; at this point, this cannot easily be explained. Accordingly, other strategies that more specifically target pathophysiological disorders in septic patients must be pursued to counteract these developments. With the approval of APC, new hope has been raised regarding the success of such strategies in general, including some of the emerging new strategies that have been discussed here. The development of new diagnostic tools that allow more accurate determination of the immune/inflammatory status of a septic patient may significantly contribute to the success of strategies that are based on defined and specific disorders in the context of sepsis.

1. Angus, D.C., et al. 2001. Epidemiology of severe sepsis in the United States: analysis of incidence, outcome, and associated costs of care. Crit. Care Med. 29:1303-1310.

2. Martin, G.S., Mannino, D.M., Eaton, S., and Moss, M. 2003. The epidemiology of sepsis in the United States from 1979 through 2000. N. Engl. J. Med. 348:1546-1554.

3. Eichacker, P.Q., et al. 2002. Risk and the efficacy of antiinflammatory agents: retrospective and confirmatory studies of sepsis. Am. J. Respir. Crit. Care Med. 166:1197-1205.

4. Bone, R.C., et al. 1989. Sepsis syndrome: a valid clinical entity. Methylprednisolone Severe Sepsis Study Group. Crit. Care Med. 17:389-393.

5. Goris, R.J., te Boekhorst, T.P., Nuytinck, J.K., and Gimbráere, J.S. 1985. Multiple-organ failure. Generalized autodestructive inflammation? Arch. Surg. 120:1109-1115.

6. Nuytinck, H.K., Offermans, X.J., Kubat, K., and Goris, J.A. 1988. Whole-body inflammation in trauma patients. An autopsy study. Arch. Surg. 123:1519-1524.

7. Bone, R.C., et al. 1992. Definitions for sepsis and organ failure and guidelines for the use of innovative therapies in sepsis. The ACCP/SCCM Consensus Conference Committee. American College of Chest Physicians/Society of Critical Care Medicine. Chest. 101:1644-1655.

8. Bone, R.C., Sprung, C.L., and Sibbald, W.J. 1992. Definitions for sepsis and organ failure. Crit. Care Med. 20:724-726.

9. Levy, M.M., et al. 2003. 2001 SCCM/ESICM/ACCP/ATS/SIS International Sepsis Definitions Conference. Crit. Care Med. 31:1250-1256.

10. Thomas, L. 1972. Germs. N. Eng. J. Med. 287:553-555.

11. Bennett, I.L., et al. 1963. The effectiveness of hydrocortisone in the management of severe infection. JAMA. 183:462-465.

12. Davis, C.E., Brown, K.R., Douglas, H., Tate, W.J., 3rd, and Braude, A.I. 1969. Prevention of death from endotoxin with antisera. I. The risk of fatal anaphylaxis to endotoxin. J. Immunol. 102:563-572. 
13. Cohen, J. 1999. Adjunctive therapy in sepsis: a critical analysis of the clinical trial programme. Br. Med. Bull. 55:212-225.

14. Michie, H.R., et al. 1988. Tumor necrosis factor and endotoxin induce similar metabolic responses in human beings. Surgery. 104:280-286.

15. Michie, H.R., et al. 1988. Detection of circulating tumor necrosis factor after endotoxin administration. N. Engl. J. Med. 318:1481-1486.

16. Beutler, B., Milsark, I.W., and Cerami, A.C. 1985. Passive immunization against cachectin/tumor necrosis factor protects mice from lethal effect of endotoxin. Science. 229:869-871.

17. Tracey, K.J., et al. 1986. Shock and tissue injury induced by recombinant human cachectin. Science. 234:470-474.

18. Tracey, K.J., et al. 1987. Anti-cachectin/TNF monoclonal antibodies prevent septic shock during lethal bacteraemia. Nature. 330:662-664.

19. Reinhart, K., and Karzai, W. 2001. Anti-tumor necrosis factor therapy in sepsis: update on clinical trials and lessons learned. Crit. Care Med. 29(Suppl.):S121-S125.

20. Eskandari, M.K., et al. 1992. Anti-tumor necrosis factor antibody therapy fails to prevent lethality after cecal ligation and puncture or endotoxemia. J. Immunol. 148:2724-2730.

21. Newcomb, D., Bolgos, G., Green, L., and Remick, D.G. 1998. Antibiotic treatment influences outcome in murine sepsis: mediators of increased morbidity. Shock. 10:110-117.

22. Girardin, E., Grau, G.E., Dayer, J.M., Roux-Lombard, P., and Lambert, P.H. 1988. Tumor necrosis factor and interleukin-1 in the serum of children with severe infectious purpura. N. Engl. J. Med. 319:397-400.

23. Hotchkiss, R.S., and Karl, I.E. 2003. The pathophysiology and treatment of sepsis. N. Engl. J. Med. 348:138-150.

24. Riedemann, N.C., and Ward, P.A. 2003. Anti-inflammatory strategies for the treatment of sepsis. Expert Opin. Biol. Ther. 3:339-350.

25. Annane, D., et al. 2002. Effect of treatment with low doses of hydrocortisone and fludrocortisone on mortality in patients with septic shock. JAMA. 288:862-871.

26. Riedemann, N.C., Guo, R.F., and Ward, P.A. 2003. Novel strategies for the treatment of sepsis. Nat. Med. 9:517-524.

27. Fisher, C.J., Jr., et al. 1996. Treatment of septic shock with the tumor necrosis factor receptor:Fc fusion protein. The Soluble TNF Receptor Sepsis Study Group. N. Engl. J. Med. 334:1697-1702.

28. Bernard, G.R., et al. 2001. Efficacy and safety of recombinant human activated protein C for severe sepsis. N. Engl. J. Med. 344:699-709.

29. Healy, D.P. 2002. New and emerging therapies for sepsis. Ann. Pharmacother. 36:648-654.

30. Riewald, M., Petrovan, R.J., Donner, A., Mueller, B.M., and Ruf, W. 2002. Activation of endothelial cell protease activated receptor 1 by the protein C pathway. Science. 296:1880-1882.

31. Siegel, J.P. 2002. Assessing the use of activated protein C in the treatment of severe sepsis. N. Engl. J. Med. 347:1030-1034.

32. Manns, B.J., Lee, H., Doig, C.J., Johnson, D., and Donaldson, C. 2002. An economic evaluation of activated protein $\mathrm{C}$ treatment for severe sepsis. N. Engl. J. Med. 347:993-1000

33. Warren, B.L., et al. 2001. Caring for the critically ill patient. High-dose antithrombin III in severe sepsis: a randomized controlled trial. JAMA. 286:1869-1878.

34. Oberholzer, C., Oberholzer, A., Clare-Salzler, M., and Moldawer, L.L. 2001. Apoptosis in sepsis: a new target for therapeutic exploration. FASEB J. 15:879-892.

35. Hotchkiss, R.S., et al. 1999. Overexpression of Bcl-2 in transgenic mice decreases apoptosis and improves survival in sepsis. J. Immunol. 162:4148-4156.

36. Hotchkiss, R.S., et al. 1999. Prevention of lymphocyte cell death in sepsis improves survival in mice. Proc. Natl. Acad. Sci. U. S. A. 96:14541-14546.

37. Hotchkiss, R.S., et al. 2000. Caspase inhibitors improve survival in sepsis: a critical role of the lymphocyte. Nat. Immunol. 1:496-501.

38. Coopersmith, C.M., et al. 2002. Inhibition of intestinal epithelial apoptosis and survival in a murine model of pneumonia-induced sepsis. JAMA. 287:1716-1721.

39. Coopersmith, C.M., et al. 2002. Overexpression of Bcl-2 in the intestinal epithelium improves survival in septic mice. Crit. Care Med. 30:195-201.

40. Hotchkiss, R.S., et al. 2003. Adoptive transfer of apoptotic splenocytes worsens survival, whereas adoptive transfer of necrotic splenocytes improves survival in sepsis. Proc. Natl. Acad. Sci. U. S. A. 100:6724-6729.

41. Wang, H., et al. 1999. HMG-1 as a late mediator of endotoxin lethality in mice. Science. 285:248-251.

42. Wang, H., Yang, H., Czura, C.J., Sama, A.E., and Tracey, K.J. 2001. HMGB1 as a late mediator of lethal systemic inflammation. Am. J. Respir. Crit. Care Med. 164:1768-1773.

43. Andersson, U., et al. 2000. High mobility group 1 protein (HMG-1) stimulates proinflammatory cytokine synthesis in human monocytes. J. Exp. Med. 192:565-570.
44. Fiuza, C., et al. 2002. Inflammatory promoting activity of HMGB1 on human microvascular endothelial cells. Blood. 101:2652-2660.

45. Sappington, P.L., et al. 2002. HMGB1 B box increases the permeability of Caco-2 enterocytic monolayers and impairs intestinal barrier function in mice. Gastroenterology. 123:790-802.

46. Ulloa, L., et al. 2002. Ethyl pyruvate prevents lethality in mice with established lethal sepsis and systemic inflammation. Proc. Natl. Acad. Sci. U. S. A. 99:12351-12356.

47. Calandra, T., et al. 2000. Protection from septic shock by neutralization of macrophage migration inhibitory factor. Nat. Med. 6:164-170.

48. Bozza, M., et al. 1999. Targeted disruption of migration inhibitory factor gene reveals its critical role in sepsis. J. Exp. Med. 189:341-346.

49. Bernhagen, J., et al. 1993. MIF is a pituitary-derived cytokine that potentiates lethal endotoxaemia. Nature. 365:756-759.

50. Rossi, A.G., et al. 1998. Human circulating eosinophils secrete macrophage migration inhibitory factor (MIF). Potential role in asthma. J. Clin. Invest. 101:2869-2874.

51. Rice, E.K., et al. 2003. Induction of MIF synthesis and secretion by tubular epithelial cells: a novel action of angiotensin II. Kidney Int. 63:1265-1275.

52. Arndt, U., et al. 2002. Release of macrophage migration inhibitory factor and CXCL8/interleukin-8 from lung epithelial cells rendered necrotic by influenza A virus infection. J. Virol. 76:9298-9306.

53. Calandra, T., Bernhagen, J., Mitchell, R.A., and Bucala, R. 1994. The macrophage is an important and previously unrecognized source of macrophage migration inhibitory factor. J. Exp. Med. 179:1895-1902.

54. Calandra, T., et al. 1995. MIF as a glucocorticoid-induced modulator of cytokine production. Nature. 377:68-71.

55. Lehmann, L.E., et al. 2001. Plasma levels of macrophage migration inhibitory factor are elevated in patients with severe sepsis. Intensive Care Med. 27:1412-1415.

56. Gando, S., et al. 2001. Macrophage migration inhibitory factor is a critical mediator of systemic inflammatory response syndrome. Intensive Care Med. 27:1187-1193.

57. Shin, H.S., Snyderman, R., Friedman, E., Mellors, A., and Mayer, M.M. 1968. Chemotactic and anaphylatoxic fragment cleaved from the fifth component of guinea pig complement. Science. 162:361-363.

58. Goldstein, I.M., and Weissmann, G. 1974. Generation of C5-derived lysosomal enzyme-releasing activity (C5a) by lysates of leukocyte lysosomes. J. Immunol. 113:1583-1588.

59. Sacks, T., Moldow, C.F., Craddock, P.R., Bowers, T.K., and Jacob, H.S. 1978. Oxygen radicals mediate endothelial cell damage by complement-stimulated granulocytes. An in vitro model of immune vascular damage. J. Clin. Invest. 61:1161-1167.

60. Schumacher, W.A., Fantone, J.C., Kunkel, S.E., Webb, R.C., and Lucchesi, B.R. 1991. The anaphylatoxins C3a and C5a are vasodilators in the canine coronary vasculature in vitro and in vivo. Agents Actions. 34:345-349.

61. Guo, R.F., et al. 2000. Protective effects of anti-C5a in sepsis-induced thymocyte apoptosis. J. Clin. Invest. 106:1271-1280.

62. Riedemann, N.C., et al. 2002. C5a receptor and thymocyte apoptosis in sepsis. FASEB J. 16:887-888.

63. Czermak, B.J., et al. 1999. Protective effects of C5a blockade in sepsis. Nat. Med. 5:788-792.

64. Huber-Lang, M.S., et al. 2002. Protection of innate immunity by C5aR antagonist in septic mice. FASEB J. 16:1567-1574.

65. Riedemann, N.C., et al. 2002. Increased C5a receptor expression in sepsis. J. Clin. Invest. 110:101-108. doi:10.1172/JCI200215409.

66. Hangen, D.H., et al. 1989. Complement levels in septic primates treated with anti-C5a antibodies. J. Surg. Res. 46:195-199.

67. Stevens, J.H., et al. 1986. Effects of anti-C5a antibodies on the adult respiratory distress syndrome in septic primates. J. Clin. Invest. 77:1812-1816.

68. Nakae, H., et al. 1994. Serum complement levels and severity of sepsis. Res. Commun. Chem. Pathol. Pharmacol. 84:189-195.

69. Nakae, H., Endo, S., Inada, K., and Yoshida, M. 1996. Chronological changes in the complement system in sepsis. Surg. Today. 26:225-229.

70. Bengtson, A., and Heideman, M. 1988. Anaphylatoxin formation in sepsis. Arch. Surg. 123:645-649.

71. Huber-Lang, M.S., et al. 2002. Complement-induced impairment of innate immunity during sepsis. J. Immunol. 169:3223-3231.

72. Guo, R.F., et al. 2003. Neutrophil C5a receptor and outcome in sepsis. FASEB J. In press.

73. Riedemann, N.C., et al. 2003. Regulation by C5a of neutrophil activation during sepsis. Immunity. In press.

74. Laudes, I.J., et al. 2002. Anti-c5a ameliorates coagulation/fibrinolytic protein changes in a rat model of sepsis. Am. J. Pathol. 160:1867-1875.

75. Rivers, E., et al. 2001. Early goal-directed therapy in the treatment of severe sepsis and septic shock. N. Engl. J. Med. 345:1368-1377.

76. van den Berghe, G., et al. 2001. Intensive insulin therapy in the critically ill patients. N. Engl. J. Med. 345:1359-1367. 